\title{
Personality Profile of Trait Consciousness of Male and Female Sports Persons
}

\author{
Poonam Joshi ${ }^{1 *}$, Dr. B. K. Bhardwaj ${ }^{2}$
}

\section{ABSTRACT}

The personality of an individual has important implications for the performance of all sorts of activities including sports and games. The Five Factor Model of personality traits have been reported to be reliable predictors of performance in many studies across the globe. The present study aimed to understand the distribution of consciousness personality profile in terms of gender and domicile of the participants in individual and team games. Four hundred male and female sports persons with different scores of trait of consciousness served as the participants in the present study. Their sports achievements in individual and team games were observed. The results of the present study evinced that sportspersons of team games scored higher on consciousness than did the sportspersons playing in individual games. The female participants showed relatively higher mean consciousness score in comparison to their male counterparts. Furthermore, the players having rural affiliations demonstrated higher mean consciousness score as compared to those who belonged to urban background. The main effect of gender on consciousness was also exhibited to have statistical significance along with statistically significant interactions between gender and background, game type and background as well as game type, gender and background. The results have been explained in the light of current theories of personality and sports achievements. The results evinced the role of gender, game types and domicile in shaping the personality trait of consciousness in sports activities the participants. The results of the study have important implications for researchers, academicians, sportspersons, policy makers and administrators. Future directions of research have also been discussed.

Keywords: Consciousness, Personality, Individual Game, Team Game, Domicile.

\footnotetext{
${ }^{1}$ Research Scholar, Department of Physical Education, Mewar University, NH-79, Gangrar, Chittorgarh, Rajasthan India

${ }^{2}$ Associate Professor, Department of Physical Education, Baiswara P. G. College, Lalganj, Raebereli, U. P. India *Responding Author

(C) 2016, P Joshi, B Bhardwaj; licensee IJIP. This is an Open Access Research distributed under the terms of the Creative Commons Attribution License (http://creativecommons.org/licenses/by/2.0), which permits unrestricted use, distribution, and reproduction in any Medium, provided the original work is properly cited.
} 


\section{Personality Profile of Trait Consciousness of Male and Female Sports Persons}

The abiding role of personality in enhancing and maintaining the sports performance has been acknowledged and well documented in psychological literature. Sportspersons with the requisite "mental toughness" and certain personality attributes have reported to be more successful in all walks of life. Certain type of personality traits have been reported to be associated with success and better performance on various indicators and are capable of learning a broad range of psychological skills that can play a critical role in learning and performance of expected sports skills. Due to this fact, a host of researches have been conducted and being conducted to understand the role of personality in human performance of various sorts (Tiwari, 2011a). These personality traits are not associated only with performance on tasks of psychomotor and athletic nature but also with various kinds of cognitive indices. In many studies, it has been reported that introverts and extraverts differ in their ability on eyewitness performance (Tiwari, 2010a; Tiwari, 2012), source-monitoring (Tiwari, 2010b; Tiwari, 2010c; Tiwari, 2011b; Tiwari, 2011d), judgement of learning (Tiwari, 2011c; Tiwari, 2015).

In recent years, the Five Factor Model (FFM) of personality namely Neuroticism, Extraversion, Agreeableness, Openness to experience, and Conscientiousness, has emerged as the most influential model of personality to explain the human performance on various indices and variety of behaviours (McAdams, 1997). Costa and McCrae (1992) believed that there are four reasons behind this. First, these constructs are enduring traits as they are based on longitudinal research and spouse rating studies. Second, these ratings were found within other personality systems and within natural language spoken by individuals. Third, these dimensions were found across age, sex, race and language groups. And lastly, based on evidence of hereditability studies, these factors appeared to have some biological basis.

The Big five personality factors have been reported to be able to measure different traits in personality without overlapping. In addition, the Big Five personality traits have shown consistency in interviews, self-descriptions, and observations. Each factor of the model comprised of a cluster of correlated specific traits. The extraversion consists of gregariousness, assertiveness, excitement seeking, warmth, activity, and positive emotions whereas openness to experience entails appreciation for art, emotion, adventure, unusual ideas, curiosity, and variety of experience. A person with Conscientiousness tendency exhibits self-discipline, act dutifully, and aim for achievement; planned rather than spontaneous behaviour; organized, and dependable. The agreeableness contains tendency to be compassionate and cooperative rather than suspicious and antagonistic towards others. It is also a measure of one's' trusting and helpful nature, and whether a person is generally well tempered or not. Lastly, an individual with neuroticism tendency is inclined to experience unpleasant emotions easily, such as anger, anxiety, depression, or vulnerability (Toegel \& Barsoux, 2012).

With broad and comprehensive attributes, the Big Five traits are powerful in predicting and explaining actual behaviour in many situations and prediction of actual behaviour and

(C) The International Journal of Indian Psychology, ISSN 2348-5396 (e)| ISSN: 2349-3429 (p) | 109 
performance with primary level traits are more effective (Paunonon \& Ashton, 2001). Industriousness and orderliness are two major attributes of conscientiousness which are very reliable in predicting human behaviour and performance. It comprised of the tendency to show self-discipline, act dutifully, and aim for achievement against measures or outside expectations. The trait shows a preference for planned rather than spontaneous behaviour. It influences the way in which we control, regulate, and direct our impulses. The average level of conscientiousness rises among young adults and then declines among older adults.

The predictability of these five factors has been verified by researchers in occupational and health psychology (Hogan, Hogan, \& Roberts, 1996), psychopathology (Costa \& McCrae, 1990), depression, bipolar disorder, and borderline personality disorders (Costa \& McCrae, 1990; Wiggins \& Pincus, 1989), obsessive compulsive disorders (Wiggins \& Pincus, 1989). Further, these factors have been found to be associated with HIV risk behaviour, and risky sexual behaviours (Miller, Lynam, Zimmerman, Logan, Leukefeld, \& Clayton, 2004). The conscientiousness and agreeableness have reported to related with job performance (Barrick, Stewart \& Piotrowski, 2002). Thus, McCrae and John (1992) argued that the FFM was applicable across most applied settings and can be used in multiple disciplines. Conscientiousness and Openness have been linked to learning styles that often lead to academic success and higher grades like synthesis analysis and methodical study. As the conscientiousness and openness have been shown to predict various learning styles, it is suggested that the individuals who possess characteristics like discipline, determination, and curiosity are more likely to engage in all types of learning styles. According to Komarraju, Karau, Schmeck \& Avdic (2011), conscientiousness and agreeableness are positively related with the learning styles, whereas neuroticism was negatively related with those four. Furthermore, extraversion and openness were only positively related to elaborative processing, and openness itself correlated with higher academic achievement.

The above review of earlier scientific work evinced that the personality attributes of the individual has important implications in a various areas of human functioning and performance. Most of the earlier work has been associated with extraversion and neuroticism with very limited studies on consciousness comprising various areas of human activities. The attributes comprising conscientiousness trait such as self-discipline, act dutifully, and achievement-orientation; planned behaviour; organized and dependable character might have important role in shaping the sports performance and other kinds of performance. In this background, the present research attempted to unveil the consciousness personality profile of male and female sports sportspersons belonging to individual and team games with rural and urban affiliations. 


\section{Personality Profile of Trait Consciousness of Male and Female Sports Persons}

\section{Objectives:}

The major objectives of the present study were as follows:

1. To study the consciousness personality profile of the sportspersons of individual and team games.

2. To compare the differences in consciousness personality profile of males and female sportspersons.

\section{METHODS}

\section{Sample:}

400 volunteer sportspersons (200 males and 200 female sportspersons) of different Colleges affiliated to Dr. Ram Manohar Lohia Avadh University, Faizabad, Uttar Pradesh, India, playing at intercollegiate levels in 3 individual and 3 team games, age ranging from 18 to 25, served as participants for the present study. Team games included in the study were football, hockey, basketball, volleyball and cricket, while the individual games were badminton, athletics, table tennis, wrestling and chess.

\section{Tool:}

The Big Five Inventory (McCrae \& Costa, 1989) was used to measures the extraversion as identified in The Five Factor Model of personality. This is a forty four item scale with acceptable psychometric properties (John, Donahue, and Kentle, 1991). This is a brief inventory allowing efficient and flexible assessment of the five dimensions. The alpha reliabilities of the BFI scales typically range from .75 to .90 and average above .80; three-month test-retest reliabilities range from .80 to .90, with a mean of .85 (John \& Srivastava, 1999). Across all five factors, the mean of the convergent validity correlations across instruments was .75. The BFI and TDA showed the strongest convergence (mean $r=.81$ ), followed by the BFI and NEO-FFI (mean $r=.73$ ), and finally the TDA and NEO-FFI (mean $r=.68$ ). Overall, discriminant correlations were low; absolute values averaged .21 for the TDA, .17 for the NEO-FFI, and .20 for the BFI. Only scores on the consciousness factor of personality of the participants have been used in this article.

\section{Procedure:}

With collection of biographic details, The Big Five Inventory was administered on the participants. The face sheet of the booklet contained general instructions. In order to facilitate reporting of authentic experiences, information that could unveil the identity the respondents were not sought. There were separate specific instructions for each of the measures included in the booklet. Each and every participant was dealt with individually and in case of any ambiguity, the statement/statements were made clear to the participants. Respondents completed the all measures between 30 to 40 minutes. The mean, Standard Deviation (SD) and Analysis of Variance (ANOVA) have been applied to analyze the obtained data. 


\section{RESULTS}

The details presented in Table 1 demonstrates that sportspersons of team games scored greater on conscientiousness $(\mathrm{M}=33.43, \mathrm{SD}=6.15)$ than did the sportspersons of individual games $(\mathrm{M}=$ 28.35, SD = 5.41).

Table 1: Pattern of conscientiousness across game type, gender and societal background

\begin{tabular}{|c|c|c|c|c|}
\hline Game Type & Gender & Background & Mean & SD \\
\hline \multirow{9}{*}{ Individual } & \multirow{3}{*}{ Males } & Rural & 24.90 & 3.48 \\
\hline & & Urban & 25.90 & 4.15 \\
\hline & & Total & 25.40 & 3.85 \\
\hline & \multirow{3}{*}{ Females } & Rural & 31.00 & 4.87 \\
\hline & & Urban & 31.60 & 5.44 \\
\hline & & Total & 31.30 & 5.15 \\
\hline & \multirow{3}{*}{ Total } & Rural & 27.95 & 5.21 \\
\hline & & Urban & 28.75 & 5.60 \\
\hline & & Total & 28.35 & 5.41 \\
\hline \multirow{9}{*}{ Team } & \multirow{3}{*}{ Males } & Rural & 28.90 & 4.79 \\
\hline & & Urban & 29.90 & 4.53 \\
\hline & & Total & 29.40 & 4.66 \\
\hline & \multirow{3}{*}{ Females } & Rural & 39.60 & 1.70 \\
\hline & & Urban & 35.30 & 5.57 \\
\hline & & Total & 37.45 & 4.63 \\
\hline & \multirow{3}{*}{ Total } & Rural & 34.25 & 6.46 \\
\hline & & Urban & 32.60 & 5.73 \\
\hline & & Total & 33.43 & 6.15 \\
\hline \multirow{9}{*}{ Total } & \multirow{3}{*}{ Males } & Rural & 26.90 & 4.63 \\
\hline & & Urban & 27.90 & 4.77 \\
\hline & & Total & 27.40 & 4.71 \\
\hline & \multirow{3}{*}{ Females } & Rural & 35.30 & 5.64 \\
\hline & & Urban & 33.45 & 5.79 \\
\hline & & Total & 34.38 & 5.78 \\
\hline & \multirow{3}{*}{ Total } & Rural & 31.10 & 6.65 \\
\hline & & Urban & 30.68 & 5.97 \\
\hline & & Total & 30.89 & 6.32 \\
\hline
\end{tabular}

In addition, the Table 2 of $F$-ratios indicate that, the main effect of game type on conscientiousness was also found to be statistically significant, $F(1,392)=128.737, p=.000$. Females showed relatively higher conscientiousness $(\mathrm{M}=34.38, \mathrm{SD}=5.78)$ in comparison to males $(\mathrm{M}=27.40, \mathrm{SD}=4.71)$.

(c) The International Journal of Indian Psychology, ISSN 2348-5396 (e)| ISSN: 2349-3429 (p) | 112 
Personality Profile of Trait Consciousness of Male and Female Sports Persons

Table 2: Analyses of variances of conscientiousness as functions of game type, gender and societal background

\begin{tabular}{|l|c|c|c|c|}
\hline \multicolumn{1}{|c|}{ Source of variance } & df & Mean Square & $\boldsymbol{F}$ & $\boldsymbol{p}$ \\
\hline Game Type & 1 & 2575.563 & 128.737 & .000 \\
\hline Gender & 1 & 4865.063 & 243.176 & .000 \\
\hline Background & 1 & 18.063 & .903 & .343 \\
\hline Game Type X Gender & 1 & 115.563 & 5.776 & .017 \\
\hline Game Type X Background & 1 & 150.063 & 7.501 & .006 \\
\hline Gender X Background & 1 & 203.063 & 10.150 & .002 \\
\hline Game Type X Gender X Background & 1 & 150.063 & 7.501 & .006 \\
\hline
\end{tabular}

Interactions between game type and gender, $F(1,392)=5.776, p=.017$, game type $\mathrm{X}$ background, $F(1,392)=7.501, p=.006$, and gender $X$ background, $F(1,392)=10.150, p=$ .002 , as well as, game type $\mathrm{X}$ gender $\mathrm{X}$ background, $F(1,392)=7.501, p=.006$, were found to be statistically significant (Figures 1, 2, 3 and 4).

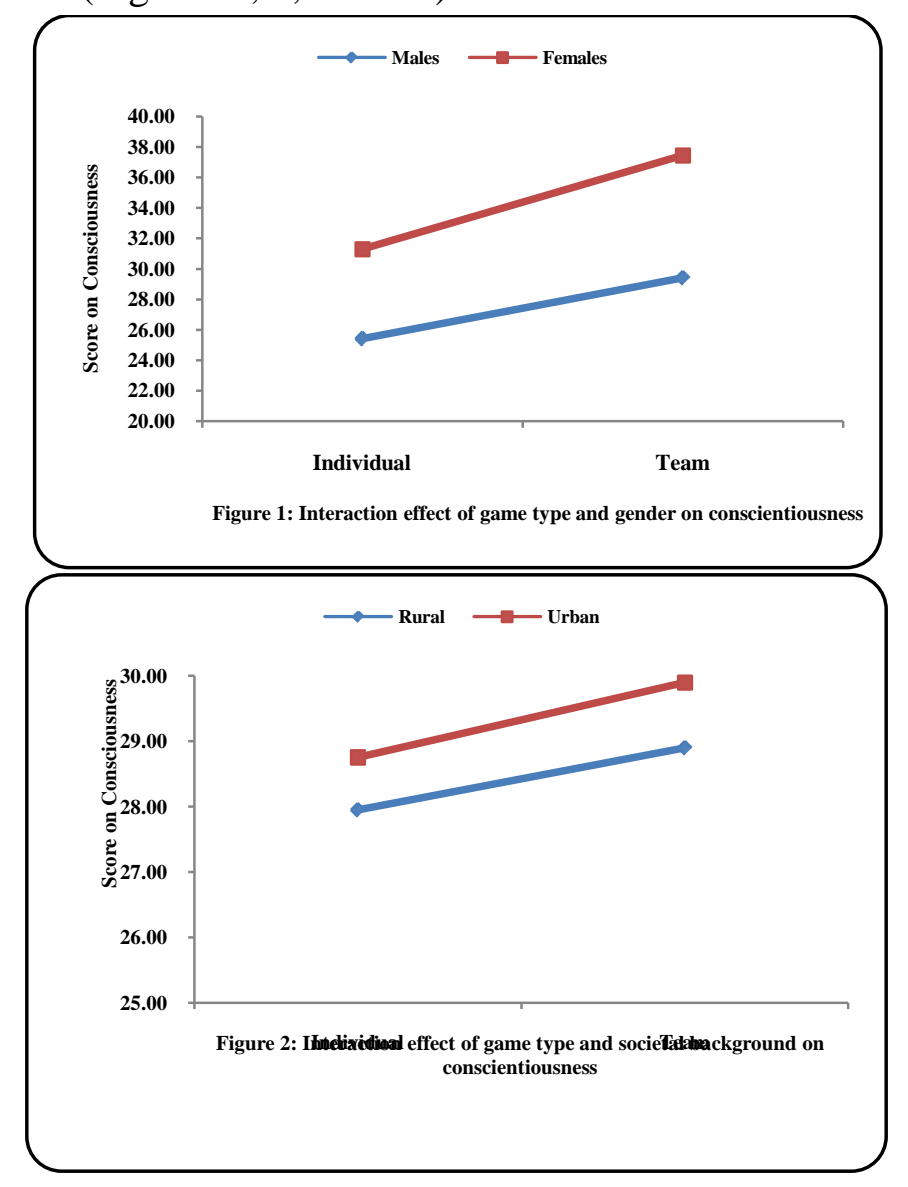

(c) The International Journal of Indian Psychology, ISSN 2348-5396 (e)| ISSN: 2349-3429 (p) | 113 
The main effect of gender on conscientiousness, $F(1,392)=243.176, p=.000$, was found to be statistically significant. However, There was very negligible difference between rural $(\mathrm{M}=$ 31.10 , $\mathrm{SD}=6.65)$ and urban $(\mathrm{M}=30.68$, $\mathrm{SD}=5.97)$ sportspersons and the main effect of societal background on conscientiousness was also not found to be statistically significant, $F$ (1, $392)=.903$.

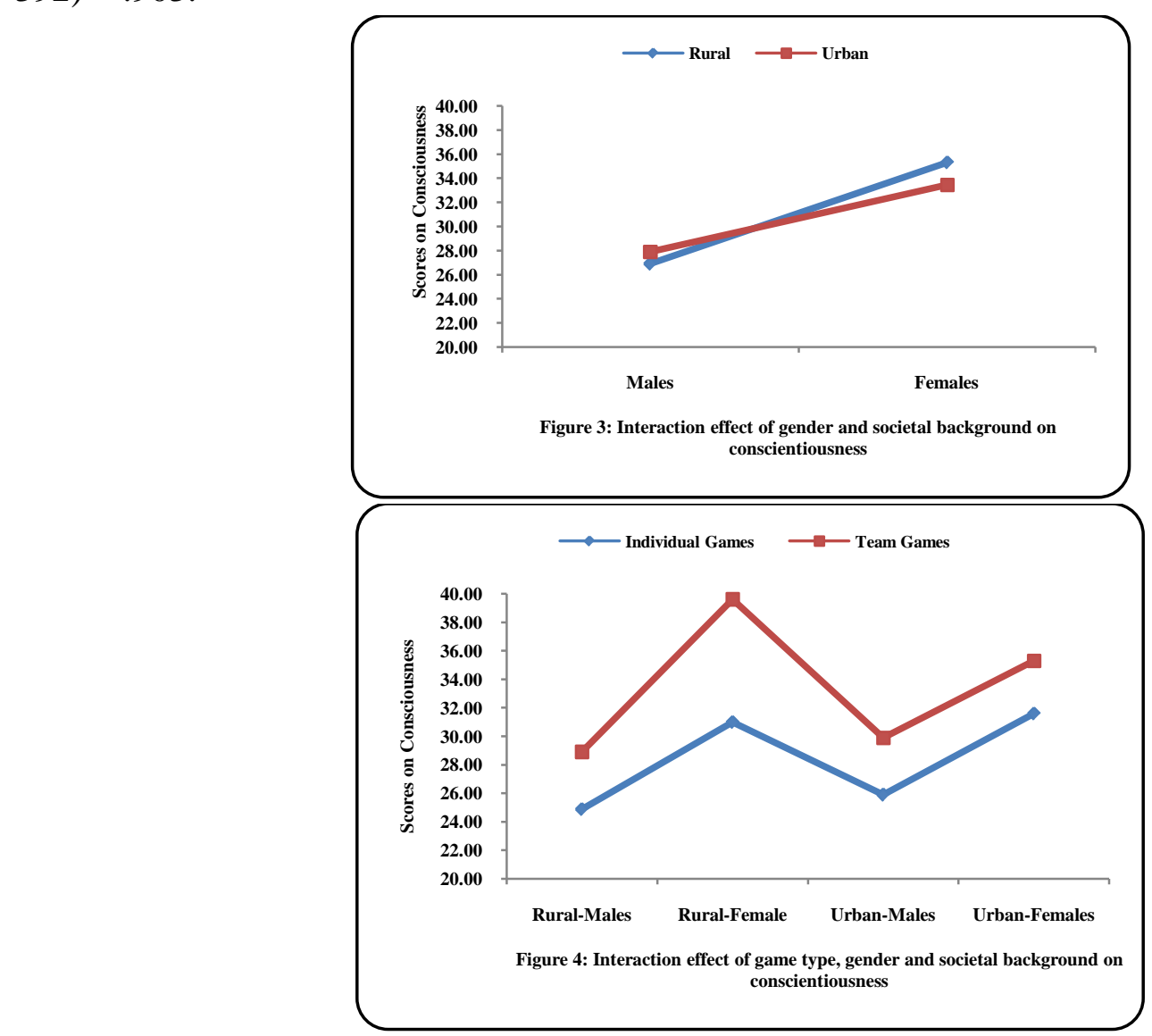

\section{DISCUSSION}

The results of the present study unequivocally indicate that there is a significant difference in consciousness personality trait among the sportspersons in terms of gender, game type and their domicile. The sportspersons of team games scored greater on conscientiousness as compared to the sportspersons of individual games which was proved by the fact that the F-ratios indicated the main effect of game type on conscientiousness. Females showed relatively higher conscientiousness scores in comparison to males. Interactions between game type and gender, game type and background and gender and background and game type, gender and background were reported to be statistically significant with no main effect of gender on conscientiousness. The rural and urban affiliation of the players did not resulted in their differences in personality attributes as shown by the main effect of societal background on conscientiousness.

The results of the study have shown that biological, biographical and socio-cultural factors shape and regulate functioning of certain personality attributes and, in turn, they impact the 
performance of the individual (Tiwari, 2010a; Tiwari, 2013). As has been claimed by earlier researches that the Big Five traits are powerful in predicting and explaining actual behaviour in many situations and prediction of actual behaviourand performance (Paunonon \& Ashton, 2001) was proved. Conscientiousness consists of industriousness and orderliness which predict human behaviour and performance. It also includes attributes of self-discipline, act dutifully, and aim for achievement against measures or outside expectations having relevance in performance. The reason behind this may be that it influences the way the impulses are controlled, regulated, and directed.

Various researches have proved that the study of consciousness and other traits of The Big Five Factors have implications in occupational and health psychology (Hogan, Hogan, \& Roberts, 1996), psychopathology (Costa \& McCrae, 1990), depression, bipolar disorder, and borderline personality disorders (Costa \& McCrae, 1990; Wiggins \& Pincus, 1989), obsessive compulsive disorders (Wiggins \& Pincus, 1989). McCrae and John (1992) have rightly argued that the FFM including consciousness are applicable across most applied settings and can be used in multiple disciplines as they are associated with learning styles affecting the performance.

The present study has significant implications in the field of sports and games along with all areas of human performance and functioning. Further research may be carried out to evaluate the efficacy of consciousness on various areas of performance. The gender differences in consciousness can be applied to allocate the roles in various setting. The small size of the sample, limited geographical area, and small number of variables are some of the limitations of the present which improved by the studies of future. The results can be applied for planning, designing of training programmes and framing educational and development plans.

\section{Acknowledgments}

The author appreciates all those who participated in the study and helped to facilitate the research process.

\section{Conflict of Interests}

The author declared no conflict of interests.

\section{REFERENCES}

Barrick, M. R., Stewart, G. L., \& Piontrowski, M. (2002). Personality and job performance: Test of the mediating effects of motivation among sales representatives. Journal of Applied Psychology, 87, 43-51.

Costa, P. T., \& McCrae, R. R. (1990). Personality disorders and the five factor model of personality. Journal of Personality Disorders, 4, 362-371. 


\section{Personality Profile of Trait Consciousness of Male and Female Sports Persons}

Costa, P. T., \& McCrae, R. R. (1992). Revised NEO Personality Inventory (NEO-PI-R) and NEO Five Factor Inventory (NEO-FFI). Professional manual. Odessa, FL: Psychological Assessment Resources.

Hogan, R., Hogan, J., \& Roberts, B. W. (1996). Personality measurement and employment decisions: Questions and answers. American Psychologist, 51, 469-477.

John, O. P., \& Srivastava, S. (1999). The Big-Five trait taxonomy: History, measurement, and theoretical perspectives. In L. A. Pervin \& O. P. John (Eds.), Handbook of personality: Theory and research (Vol. 2, pp. 102-138). New York: Guilford Press.

John, O. P., Donahue, E. M. \& Kentle, R. L. (1991). The big five inventory: Versions 4a and 54. Technical report, Institute of personality and social research, University of California, Berkeley, CA.

Komarraju, M., Karau, S. J. Schmeck, R. R., \& Avdic, A. (2011). The Big Five personality traits, learning styles, and academic achievement. Personality and Individual Differences, 51, (4), 472-477.

McAdams, D. P. (1997). A conceptual history of personality psychology. In R. Hogan, J. Johnson, \& S. Briggs (Eds.). Handbook of Personality Psychology (pp. 3-39). San Diego: Academic Press.

McCrae, R. R., \& Costa, P. T., Jr. (1989). Rotation to maximize the construct validity of factors in the NEO Personality Inventory. Multivariate Behavioral Research, 24, 107-124.

McCrae, R. R., \& John, O. P. (1992). An introduction to the five-factor model and its applications. Journal of Personality, 60, 175-215.

Miller, J. D., Lynam, D., Zimmerman, R. S., Logan, T. K., Leukefeld, C., \& Clayton, R. (2004). The utility of the five factor model in understanding risk behavior. Personality and Individual Differences, 36, 1611-1626.

Paunonen, S. V. \& Ashton, M. C. (2001). Big-five factors and facets and the prediction of behavior. Journal of Personality and Social Psychology, 81,524-539.

Tiwari, G. K. (2010a). Personality and recall accuracy of witnessed events. Perspectives in Psychological Researches, 33 (I), 225-231.

Tiwari, G. K. (2010b). Personality differences in source-monitoring of witnessed details. Anusilana, XXIX, 65-70.

Tiwari, G. K. (2010c). Research in eyewitness memory: Issues and challenges. Jigyasa, III (4), 66-71.

Tiwari, G. K. (2011a). Stress and human performance. Indo-Indian Journal of Social Science Researches, 7 (1), 40-49.

Tiwari, G. K. (2011b). The eyewitness suggestibility effect and source-attribution. Jigyasa, IV (1), 413-418.

Tiwari, G. K. (2011c). Personality and met memory judgements in witnessed events. United Journal of Awadh Scholars, 5(2), 23-30.

Tiwari, G. K. (2011d). Arousal differences in recall and source-monitoring accuracy of witnessed events. Indian Journal of Social Science Researches, 8(1-2), 29-35. 
Tiwari, G. K. (2012). The misinformation effect and fate of witnessed minutiae. Indian Journal of Community Psychology, 8 (1), 134-142.

Tiwari, G. K. (2013). Emotional suppression and eyewitness memory. JIGYASA, VI (4), 196 203.

Tiwari, G. K. (2015). Does judgement of learning predict accuracy of recall during emotional arousal? Madhya Bharati, 68 (1), 175-190.

Toegel, G.; Barsoux, J. L. (2012). "How to become a better leader". MIT Sloan Management Review. 53 (3): 51-60.

Wiggins, J., \& Pincus, A. (1989). Conceptions of personality disorders and dimensions of personality. Psychological Assessment, 1, 305-316.

How to cite this article: P Joshi, B Bhardwaj (2016), Personality Profile of Trait Consciousness of Male and Female Sports Persons, International Journal of Indian Psychology, Volume 3, Issue 4, No. 64, ISSN 2348-5396 (e), ISSN: 2349-3429 (p), DIP: 18.01.126/20160304, ISBN: 978-1365-32519-9 